\title{
Determination of concentration equilibrium of the substance being measured in a supercritical solvent with a dynamic research method
}

\author{
(C) Lenar Yu. Yarullin, ${ }^{+}$Farizan R. Gabitov, ${ }^{1 *}$ Lyudmila Y. Sabirova, ${ }^{1}$ and Polina V. Antonova ${ }^{1}$ \\ Department of Theoretical Foundations of Heat Engineering. Kazan National Research Technological \\ University. Karl Marx St., 68. Kazan, 420015. Republic of Tatarstan. Russia. \\ Phone:+7 (843)231-42-92.E-mail:yarul.lenar@gmail.com
}

\begin{abstract}
*Supervising author; ${ }^{+}$Corresponding author
Keywords: supercritical fluid, supercritical carbon dioxide, tea leaf, tannin, solubility, consumption.
\end{abstract}

\begin{abstract}
At present, there is no universal method for studying the solubility of substances in supercritical fluid media. The expediency of combining certain methods of solution saturation and composition analysis is determined by the object of study, the range of concentrations. In the case of low solubility of solids in the solvent, a flow-through system or dynamic solubility measurement method is usually used to obtain the required amount of precision weighing material.

The dynamic method for measuring the solubility of substances in supercritical carbon dioxide is not without its drawbacks, which primarily include the need to strictly control the mass flow rate of supercritical carbon dioxide in the cell with the substance being measured. With an increase in the consumption of supercritical dioxide from zero (static method) to a certain value, the concentration of the measured substance in supercritical carbon dioxide within the acceptable level of uncertainty for measuring the solubility of 4-6\% can be considered unchanged. The plateau of the concentration of the measured substance in supercritical carbon dioxide from the flow rate obtained in the diagram corresponds to the saturation state of the solvent, which is carbon dioxide and the solute, which corresponds to the concept of solubility. However, with a further increase in the consumption of carbon dioxide, the concentration begins to decrease and it can no longer be considered equilibrium. This is due to the fact that at significantly high flow rates of carbon dioxide, which is a solvent, coming into contact with the substance being dissolved, it does not have time to saturate it and, accordingly, weakly dissolves it. This concentration does not correspond to the concept of solubility.

Thus, the determination of the range of mass flow rate at which the conditional state of saturation of the solvent and the solute is reached is the most important stage in studies to measure the solubility of substances in supercritical fluids.

Based on the results of experimental data measuring the solubility of tannin in supercritical carbon dioxide, the dependences of the concentration of tannin in supercritical carbon dioxide on the mass flow rate are presented. It follows from the results that, in the flow rate range of $0-0.6 \mathrm{~g} / \mathrm{min}$, the tannin concentration in supercritical carbon dioxide is practically independent of the solvent flow rate, which is evidence of the equilibrium of this concentration and its compliance with the concept of solubility.
\end{abstract}

\section{References}

[1] R. Burk, P. Kruus. Solubilities of solids in supercritical fluids. The Canadian Journal of Chemical Engineering. 1992. Vol.70(2). P.403-407.

[2] I. Goodarznia, F. Esmaeilzadeh. Solubility of an anthracene, phenanthrene and carbazole mixture in supercritical carbone dioxide. Journal Chemical Engineering Data. 2002. Vol.47(2). P.333-338.

[3] E. Kosal, G.D. Holder. Solubility of anthracene and phenanthrene mixtures in supercritical carbon dioxide. J. Chem. Eng. Data. 1987. Vol.32. P.148-150.

[4] Q. Li, Z. Zhang, C. Zhong, Y. Liu, O. Zhou. Solubility of solid solutes in supercritical carbon dioxide with and without cosolvents. Fluid Phase Equilibria. 2003. Vol.207(1-2). P.183-192.

[5] T.W. Zerda, B. Wiegand, J. Jonas. FTIR measurements of solubilities of anthracene in supercritical $\mathrm{CO}_{2}$. J. Chemical Eng. Data. 1986. Vol.31(3). P.274-277.

[6] A.J.Ameer, A.A.Zakharov, T.R.Bilalov, R.R.Nakipov, I.R.Gabitov, Z.I.Zaripov, F.M.Gumerov. Some thermodynamic properties of the mixture «anthracene - carbon dioxide» in the supercritical fluid region of the state. Supercritical Fluids: Theory and Practice. 2015. Vol.10. No.4. P.18-35. 
DETERMINATION OF CONCENTRATION EQUILIBRIUM OF THE SUBSTANCE BEING MEASURED...

[7] A.T. Tukhvatova, R.A. Kayumov, V.F. Khairutdinov, A.A. Sagdeev, N.N. Sarimov, F.M. Gumerov., F.R. Gabitov, S.I. Volfson. Solubility of styrene in supercritical carbon dioxide. Supercritical Fluids: Theory and Practice. 2015. Vol.5. No.4. P.43-64

[8] L.Y. Yarullin, F.R. Gabitov, I.I. Zamaliev and L.Y. Sabirova. Dynamic solubility measurement of substances in supercritical fluids. Butlerov Communications. 2019. Vol.60. No.12. P.96-103. ROI: jbc02/19-60-12-96

[9] L.Y. Yarullin, F.M. Gumerov, Truong Nam Hung, I.I. Gilmutdinov, Z.I. Zaripov, F.R. Gabitov, and A.B. Remizov. The composition and structure of the tea leaves, processed in supercritical carbon dioxide. Butlerov Communications. 2016. Vol.48. No.11. P.88-100. ROI: jbc-02/16-48-11-88

[10] Z.I. Zaripov, L.Y. Yarullin, F.M. Gumerov, Truong Nam Hung, F.R. Gabitov and V.A. Kayumova. Thermal effects dissolution main tea components in supercritical carbon dioxide. Butlerov Communications. 2017. Vol.49. No.2. P.96-101. ROI: jbc-02/17-49-2-96 